\title{
Impaired functions of neural stem cells by abnormal nitric oxide-mediated signaling in an in vitro model of Niemann-Pick type C disease
}

\author{
Sun-Jung Kim ${ }^{1,2}$, Myung-Sin Lim ${ }^{1,2}$, Soo-Kyung Kang ${ }^{3}$, Yong-Soon Lee ${ }^{1,2}$, Kyung-Sun Kang ${ }^{1,2}$ \\ ${ }^{I}$ Adult Stem Cell Research Center, College of Veterinary Medicine, Seoul National University, Seoul, Republic of Korea; ${ }^{2}$ Labora- \\ tory of Stem Cell and Tumor Biology, Department of Veterinary Public Health, College of Veterinary Medicine and BK21 Program \\ for Veterinary Science, Seoul National University, Seoul, Republic of Korea, ${ }^{3}$ Department of Physiology, College of Medicine, \\ Pusan National University, Busan, Republic of Korea
}

Nitric oxide (NO) has been implicated in the promotion of neurodegeneration. However, little is known about the relationship between NO and the self-renewal or differentiation capacity of neural stem cells (NSCs) in neurodegenerative disease. In this study, we investigated the effect of NO on self-renewal of NSCs in an animal model for Niemann-Pick type C (NPC) disease. We found that NO production was significantly increased in NSCs from NPC1-deficient mice $\left(\mathrm{NPC1}^{--}\right.$), which showed reduced NSC self-renewal. The number of nestin-positive cells and the size of neurospheres were both significantly decreased. The expression of NO synthase (NOS) was increased in neurospheres derived from the brain of $\mathrm{NPC1}^{--}$mice in comparison to wild-type neurospheres. NO-mediated activation of glycogen synthase ki-

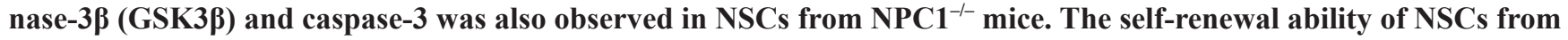
$\mathrm{NPC1}^{-/}$mice was restored by an NOS inhibitor, L-NAME, which resulted in the inhibition of GSK3 $\beta$ and caspase-3. In addition, the differentiation ability of NSCs was partially restored and the number of Fluoro-Jade C-positive degenerating neurons was reduced. These data suggest that overproduction of NO in NPC disease impaired the self-renewal of NSCs. Control of NO production may be key for the treatment of NPC disease.

Keywords: neural stem cells, nitric oxide, GSK3 $\beta$, Niemann-Pick type C1 disease, caspase-3

Cell Research (2008) 18:686-694. doi: 10.1038/cr.2008.48; published online 8 April 2008

\section{Introduction}

Neural stem cells (NSCs) have a capacity for self-renewal and can differentiate into multiple cell types, such as astrocytes, oligodendrocytes and neurons [1]. The fate of stem cells is regulated by many factors, such as Wnt/Bmp, that maintain multi-potency and suppress differentiation [2]. Additionally, Notch1 plays an important role in regulating stem cell and glial fates in mammalian CNS development [3]. Nevertheless, the mechanisms that regulate NSC fate are not completely understood.

Recently, nitric oxide (NO) has been implicated as a key

Correspondence: Kyung-Sun Kang

Tel: +82-2-880-1246; Fax: +82-2-876-7610

E-mail: kangpub@snu.ac.kr

Received 11 July 2007; revised 12 September 2007; accepted 10 December 2007; published online 8 April 2008 factor that regulates stem cell fate. For instance, Estrada et al. reported that NO decreased subventricular zone (SVZ) stem cell proliferation via inhibition of epidermal growth factor receptors (EGFR) and the phosphoinositide 3-kinases (PI3K)/AKT pathway [4]. NO is a well-characterized intracellular messenger that is involved in many physiological processes. Studies have shown that NO affects proliferation and adult neurogenesis $[5,6]$. Moreover, $\mathrm{NO}$ action on the GSK $3 \beta$ signaling pathway has been linked to neurodegenerative diseases, such as Alzheimer's disease (AD) and Parkinson's disease (PD) [7, 8].

Among the progressive neurodegerative diseases, Niemann-Pick type C (NPC) disease is an autosomal recessive disease, characterized by impaired intracellular cholesterol tracking. NPC pathology is characterized by neurofibrillary tangles (NFTs) and neuronal death [9, 10].

There are several hypotheses to explain the neurodegeneration in NPC disease. Yu et al. suggested that deficiency 
of the NPC1 gene decreases ATP levels, causing impairment of neurite outgrowth and enhanced susceptibility to free radicals. These factors accelerate neurodegeneration in $\mathrm{NPCl}^{-/}$mice [11]. Previously, we have reported that reduced NSC self-renewal in NPC-deficient mice is mediated through p38 mitogen-activated protein kinase (p38 MAPK) [12]. However, the molecular mechanism behind neurodegeneration in NPC disease remains largely unclear.

In this study, we hypothesized that NO accelerates the progression of NPC disease. To investigate this issue, we examined the role of NO activation on NSC self-renewal and differentiation in NPC1-deficient mice.

\section{Results}

Levels of NO increased and nestin expression decreased in NSCs of $\mathrm{NPCl}^{--}$mice

We examined the involvement of an NO-mediated pathway in impaired self-renewal and differentiation of NSCs in NPC1-mutated mice. NO production was measured as nitrite-nitrate release into culture medium. We showed that NSC production of $\mathrm{NO}$ in $\mathrm{NPC1}^{-/-}$mice was approxi- mately two-fold higher than that in control wild-type mice (Figure 1A). The level of NO production in NSCs from $\mathrm{NPCl}^{+/-}$heterozygous mice was similar to wild type, which may explain the lack of pathology in $\mathrm{NPC}^{+/-}$heterozygous mice.

We also investigated the levels of different NO synthase (NOS) isoforms, neuronal NOS (nNOS) and endothelial NOS (eNOS), in NSCs. We did not observe a significant difference in levels of the NOS isoforms for all genotypes (Figure 1B). Inducible NOS (iNOS) protein was detected only in NSCs from $\mathrm{NPC1}^{-/}$mice (Figures 1B, 2A and 2B). iNOS is usually induced by inflammation and oxidative stress [13]. Immunostaining studies revealed that iNOS was highly expressed in NSCs from $\mathrm{NPC}^{-/-}$mice. Expression of nestin, a neural stem and progenitor marker, was decreased in $\mathrm{NPCl}^{-/-}$mice (Figure 1C).

Previous work showed that iNOS generated high levels of NO [14] and iNOS was expressed in an animal model of neurodegeneration [15]. Our studies suggest that iNOS may stimulate the high production of NO in NSCs from $\mathrm{NPCl}^{-/}$mice.

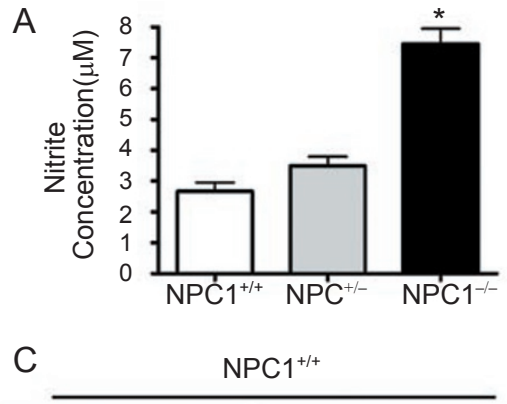

B
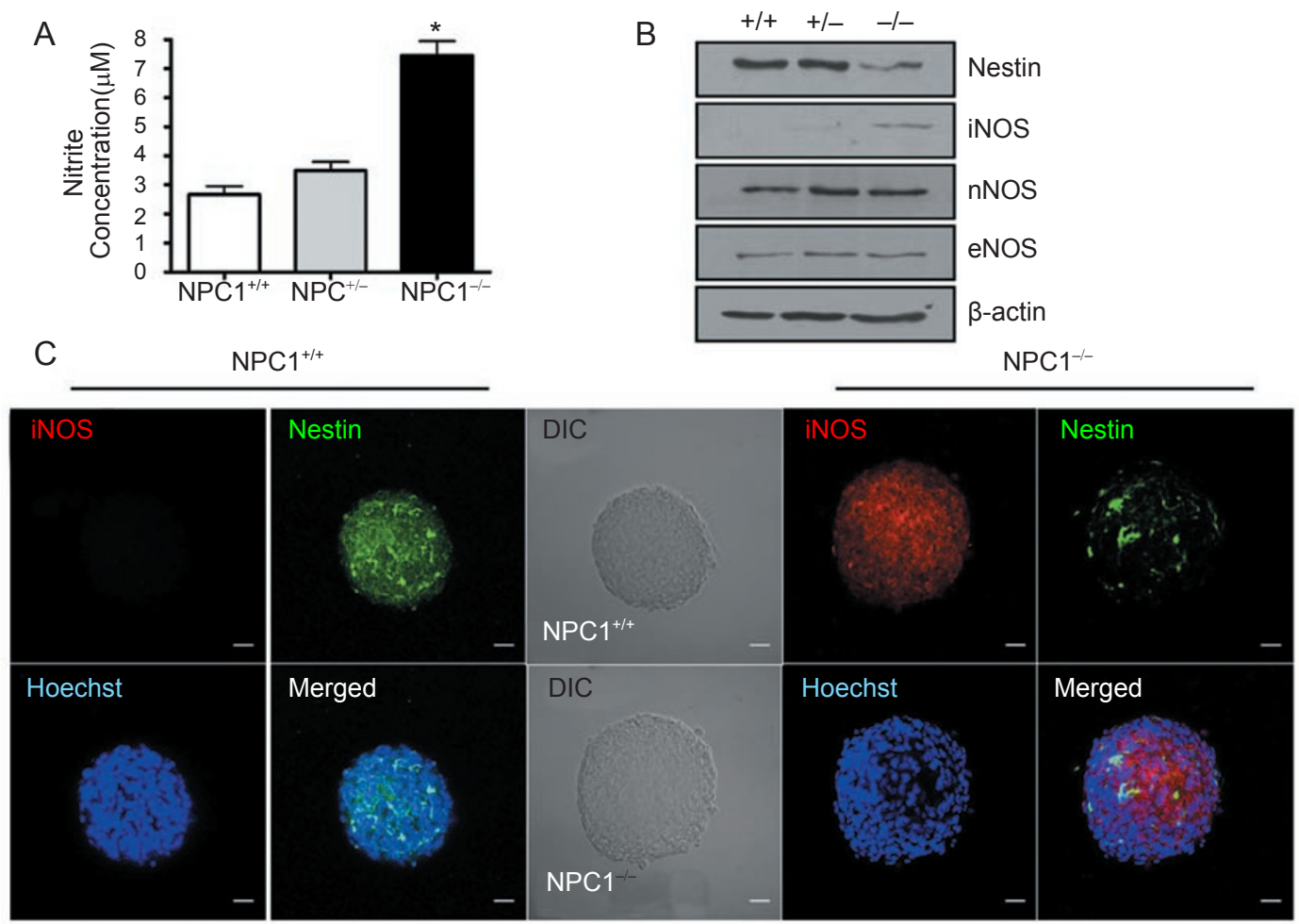

Figure 1 Nitric oxide levels increased in NSCs of NPC1 $1^{-/}$mice. (A) Nitric oxide production was elevated in NSCs from NPC1 $1^{-/-}$ mice. Results represent nitrite concentrations $(\mu \mathrm{M}), P<0.05$. (B) Protein levels of nestin, iNOS, eNOS, nNOS and $\beta$-actin were assessed by Western blotting (protein $20 \mu \mathrm{g} /$ well). (C) NSCs from wild-type mice express nestin (green) but not iNOS (red). In $\mathrm{NPC}^{-/-}$mice, nestin was weakly expressed and iNOS was strongly expressed in NSCs. Bar $=80 \mu \mathrm{m}$. 
High NO levels reduce self-renewal of NSCs through activation of GSK3 3 and caspase-3 in $\mathrm{NPCl}^{-/}$mice

To further investigate the idea that increased NO levels inhibit self-renewal of NSCs, these cells were treated with an NO donor, Spermine NONOate (SPNO, $25 \mu \mathrm{M}$ and $50 \mu \mathrm{M}$ ). The number of neurospheres was measured (Supplementary information, Figure S1A-S1C) in the presence of SPNO. We found that the NO donor significantly decreased the number and size of neurospheres in a concentration-dependent manner (Supplementary information, Figure S1C).

Recent studies have proposed that NO is involved in the regulation of self-renewal and differentiation in stem cells $[16,17]$. To investigate how high levels of NO reduce self-renewal of NSCs in $\mathrm{NPC}^{-/}$mice, we used Western blot analysis to examine the differences in NSC protein levels from all NPC1 genotypes. Although the iNOS protein was not detected in $\mathrm{NSCs}$ from $\mathrm{NPCl}^{+++}$or $\mathrm{NPC}^{+/-}$mice, iNOS levels were increased in NSCs from $\mathrm{NPCl}^{-/}$mice (Figure 2A).

Caspase- 3 is a key mediator of apoptosis and its action is enhanced by NO [18]. Activation of caspase-3 (determined by cleaved 19 and $17 \mathrm{kDa}$ fragments) was observed in NSCs from $\mathrm{NPC1}^{-/}$mice (Figure 2A). Over-expression of GSK3 $\beta$ has been shown to induce apoptosis through the activation of caspase-3 [19-21]. We investigated the levels of GSK3 $\beta$ activity by its phosphorylation status. Upregulation of GSK $3 \beta$ activity requires Tyr 216 phosphorylation, whereas its inhibition requires Ser9 phosphorylation [22].

We found that Ser9-phosphorylated GSK3 $\beta$ protein levels were significantly decreased in NSCs from $\mathrm{NPC}^{-/}$mice (Figure 2A-2C). Furthermore, immunostaining of NSCs from $\mathrm{NPC}^{-/-}$mice revealed decreased phospho-GSK3 $\beta$ Ser9 (p-GSK3 $\beta$-Ser9), increased p-GSK3 $\beta$-Tyr216 and expression of iNOS (Figure 2B). These data suggested that GSK3 $\beta$ may be activated in the NSCs from $\mathrm{NPC1}^{-}$ mice.

The $\mathrm{p}-\mathrm{AKT}$ protein is involved in cell survival and regulates GSK3 $\beta$ activity. We found that p-AKT protein was decreased in NSCs from $\mathrm{NPC1}^{-/}$mice (Figure 2A and 2D), while protein levels of phosphorylated p38 MAPK were increased, as reported previously [12]. The p38 MAPK is important for NO-induced neuronal cell death [23] (Figure $2 \mathrm{~A}$ and $2 \mathrm{E}$ ). These data indicated that iNOS might modulate GSK3 $\beta$, caspase-3, p-AKT and p38 MAPK, leading to decreased self-renewal and increased cell death of NSCs

A

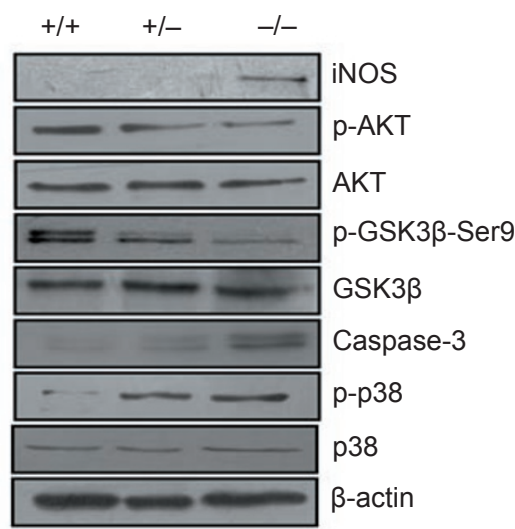

B
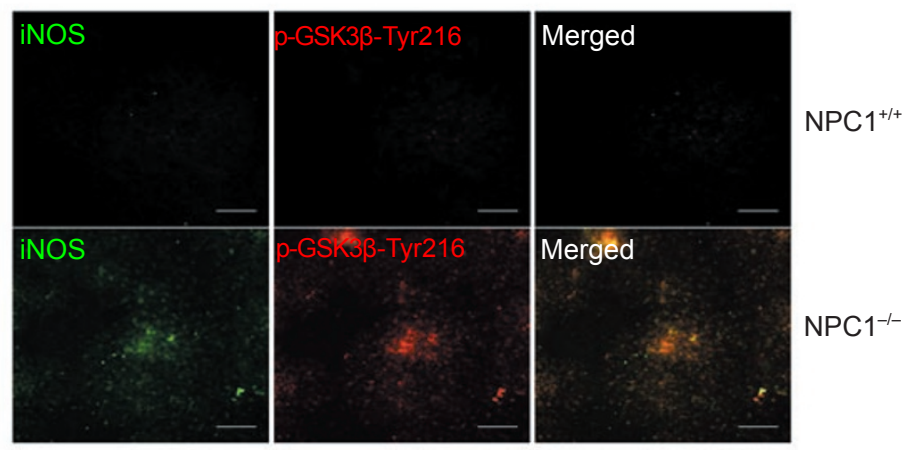

$\mathrm{C}$

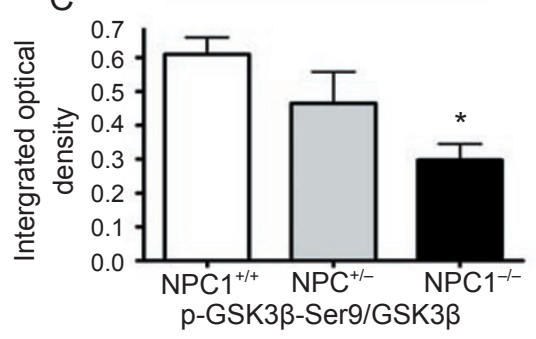

$\mathrm{D}$

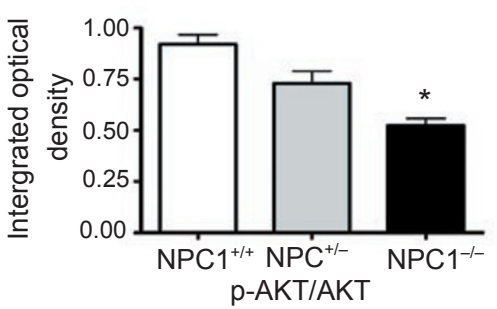

E

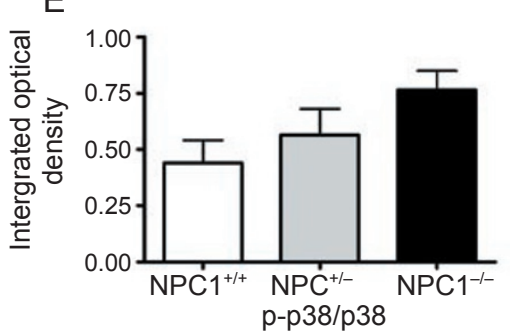

Figure 2 Nitric oxide might mediate NSC self-renewal through the activation of GSK3 $\beta$ and caspase-3 in NPC $1^{-1}$ mice. (A) Western blots show protein levels in NSCs from NPC $1^{+/+}, \mathrm{NPC}^{+/}$and $\mathrm{NPC}^{-1-}$ mice (protein $20 \mu \mathrm{g} /$ well). Proteins analyzed include iNOS, p-GSK3 $\beta$-Ser9, GSK3 $\beta$, p-AKT, AKT, p-p38, p38, caspase-3 and $\beta$-actin. (B) Immunostaining shows co-expression of iNOS (green) and p-GSK3 $\beta$-Tyr216 (red). Bar = $80 \mu \mathrm{m}$. (C) Western blots show p-GSK3 $\beta$-Ser9 protein levels normalized to GSK3 $\beta$ protein levels. (D) p-AKT protein levels were normalized to AKT by Image $\mathrm{J}$ analysis software. (E) p-p38 protein levels were normalized to $\mathrm{p} 38$ by Image $\mathrm{J}$ analysis software. Mean $\pm \mathrm{SD}$ for 3-5 independent experiments, $P<0.05$. 
A

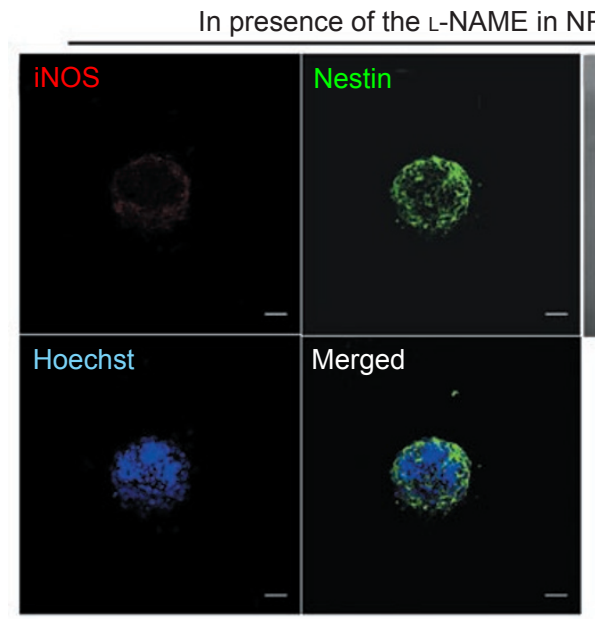

B
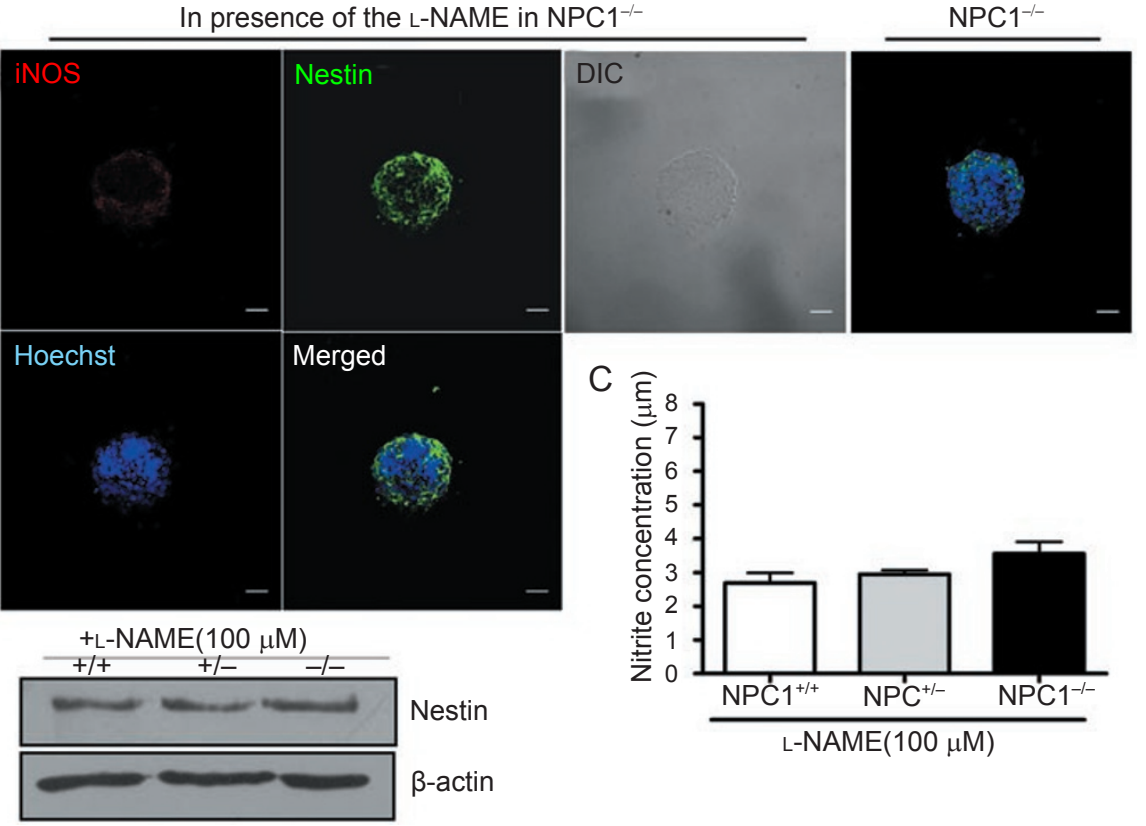

Figure 3 L-NAME decreased production of nitric oxide and increased nestin expression in NSCs from NPC1 $1^{-l-}$ mice. (A) In the presence of L-NAME, nestin expression increased but iNOS expression decreased in NSCs from NPC $1^{-1-}$ mice. (B) L-NAME $(20 \mu \mathrm{g} / \mathrm{well})$ treatment increased nestin protein levels in neurospheres from NPC1 $1^{-1-}$ mice. (C) Nitrite concentration was decreased in NSCs from $\mathrm{NPC1}^{--}$mice to wild-type levels.

A
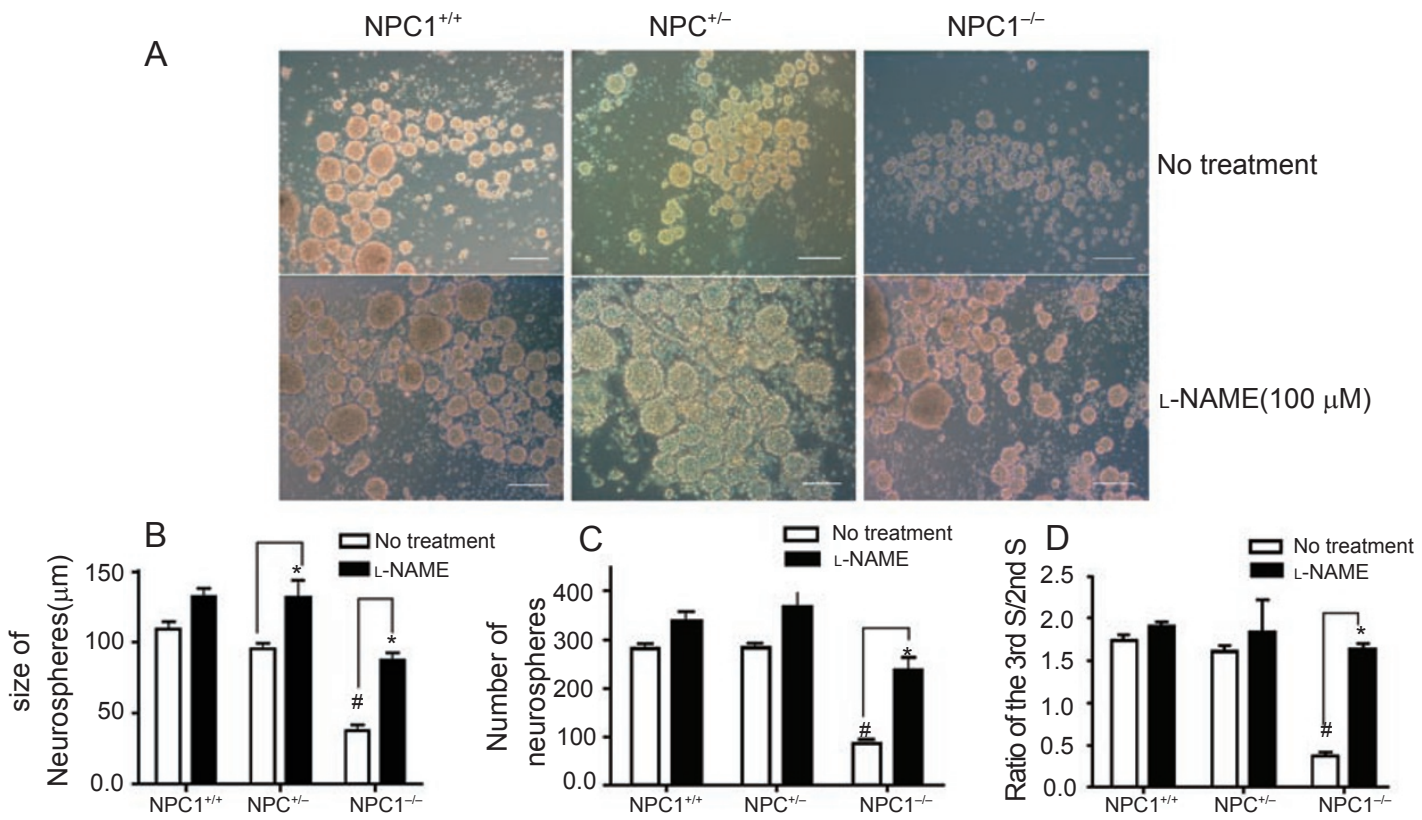

Figure 4 Neurospheres formation was increased by treatment with the NO inhibitor, L-NAME (100 $\mu$ M) in NSCs from NPC1 ${ }^{-/-}$mice. Images show typical neurospheres that were formed from E16 fetal mouse brains after 6 days. (A) L-NAME increased the formation of neurospheres. (B) The size of the neurospheres from NPC1 $1^{-/-}$mice increased in the presence of L-NAME (100 $\mu M$ ). (C) Self-renewal capacity is expressed as the number of secondary neurospheres generated per primary sub-cloning. Closed bars represent neurospheres generated in the absence of L-NAME. Open bars represent neurospheres cultured in the presence of L-NAME $(100 \mu \mathrm{M})$. (D) Ratio of the number of third neurospheres generated per subcloned second neurosphere. Mean \pm SD for 3-5 independent experiments. $P<0.05$. 
from $\mathrm{NPCl}^{-/-}$mice.

Impairment of NSC self-renewal in $\mathrm{NPCl}^{--}$mice was restored by a NO synthesis inhibitor, L-NAME

To determine if $\mathrm{NO}$ is involved in the impairment of self-renewal in NSCs from $\mathrm{NPC}^{-/-}$mice, we treated neurosphere cultures with $N^{\mathrm{G}}$-nitro-L-arginine methyl ester (L-NAME), a NO synthesis inhibitor. We treated neurospheres with different concentrations of L-NAME and investigated the formation of neurospheres to determine the effective concentration of L-NAME (Supplementary information, Figure S2).

In the presence of L-NAME $(100 \mu \mathrm{M})$, NO production in NSCs from $\mathrm{NPC}^{-1-}$ mice was abrogated as much as that of wild type (Figure 3C). Moreover, iNOS expression decreased and nestin expression increased (Figure $3 \mathrm{~A}$ and 3B).

Figure 4A shows that the formation of neurospheres corresponded to the genotypes of NPC. The number of neuro- spheres increased with L-NAME treatment in all genotypes. The number and size of neurospheres were significantly decreased in $\mathrm{NPCl}^{-/}$homozygotes compared to heterozygotes and wild type. NSC self-renewal in homozygotes was restored to a level similar to wild type (Figure 4B-4C). The size and number of neurospheres from wild type increased slightly with L-NAME. When neurospheres were replated into new dishes in the presence of L-NAME, the number of new neurospheres increased in all mouse groups. The ratio of third-generation neurospheres to second-generation neurospheres revealed that $\mathrm{NPC}^{-/}$neurospheres gave rise significantly to more daughter neurospheres in the presence of L-NAME (Figure 4D).

L-NAME, a NO synthesis inhibitor, blocked GSK3ß and caspase-3 activation in NSCs of $\mathrm{NPCl}^{--}$mice

In the presence of L-NAME, there was a significant increase in the number and size of neurospheres from $\mathrm{NPC}^{-1-}$. To determine if reduction of NO affected the GSK3 $\beta /$ cas-
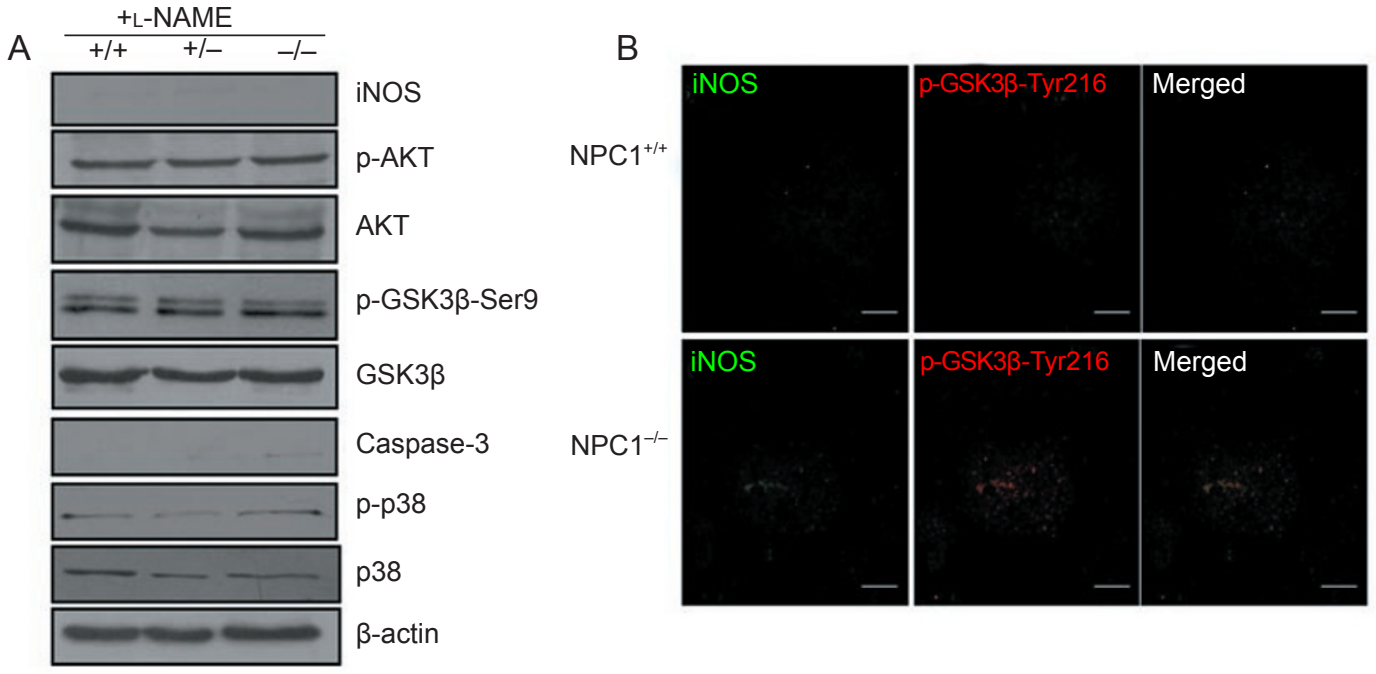

C

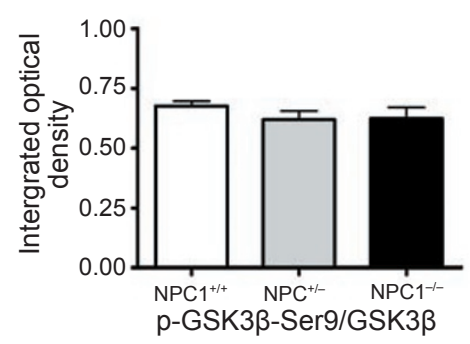

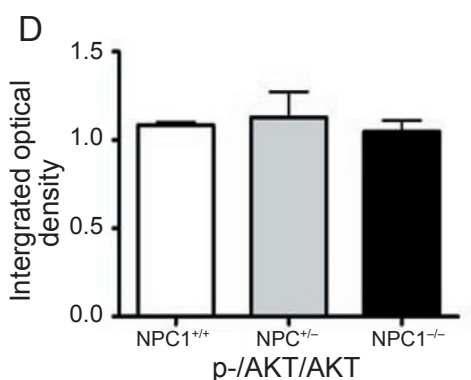

E

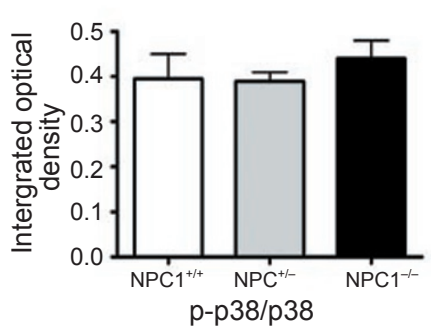

Figure $5 \mathrm{~L}-\mathrm{NAME}$ depletion of nitric oxide in NSCs from NPC1 $1^{-1-}$ may prevent neuronal cell death by decreasing activity of GSK3 $\beta$ and caspase-3. (A) Western blot results for iNOS p-GSK3 $\beta$-Ser9, GSK3 $\beta$, p-AKT, AKT, p-p38, p38, caspase-3 and $\beta$-actin. (B) Immunochemistry results show that L-NAME $(100 \mu \mathrm{M})$ treatment reduces levels of iNOS (green) and p-GSK3 $\beta$-Tyr216 (red) in NSCs from NPC1 $1^{--}$mice. Bar $=80 \mu \mathrm{m}$. (C) Western blot shows $\mathrm{p}-\mathrm{GSK} 3 \beta$-Ser9 protein levels normalized to GSK3 $\beta$ protein levels. (D) p-AKT protein level normalized to AKT by Image $\mathrm{J}$ analysis software. (E) p-p38 protein levels normalized to p38 by Image $\mathrm{J}$ analysis software. Mean $\pm \mathrm{SD}$ for 3-5 independent experiments. $P<0.05$. 
A

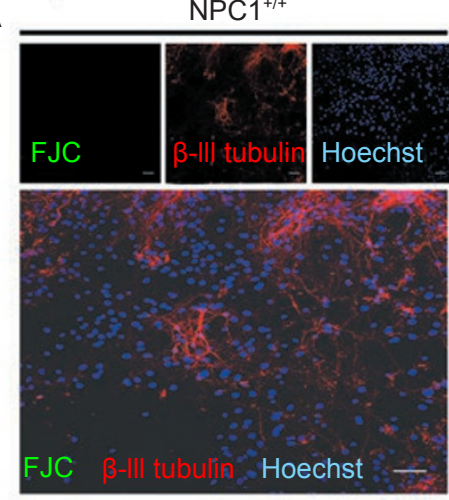

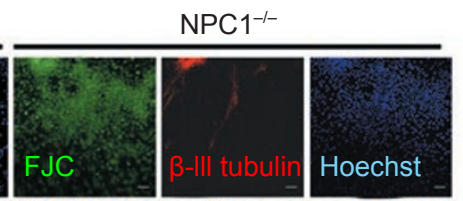
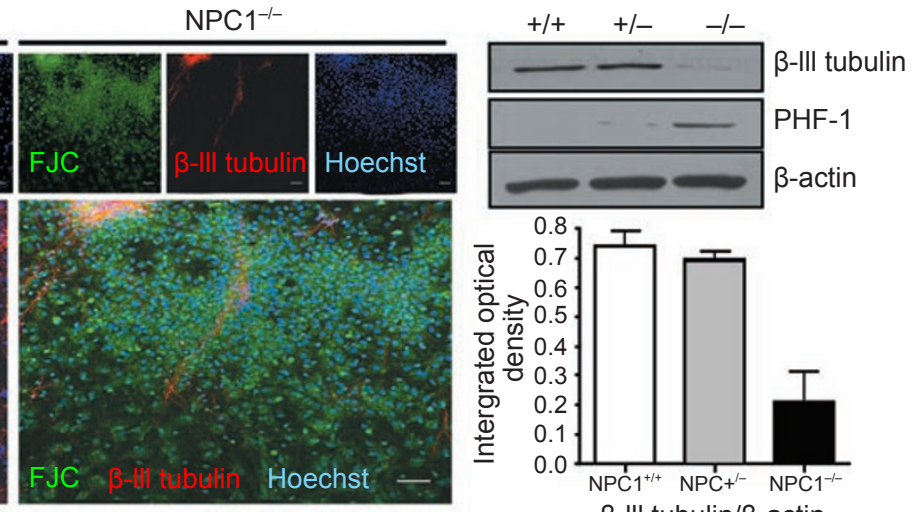

B In the presence of L-NAME in NPC1 $1^{-/-}$
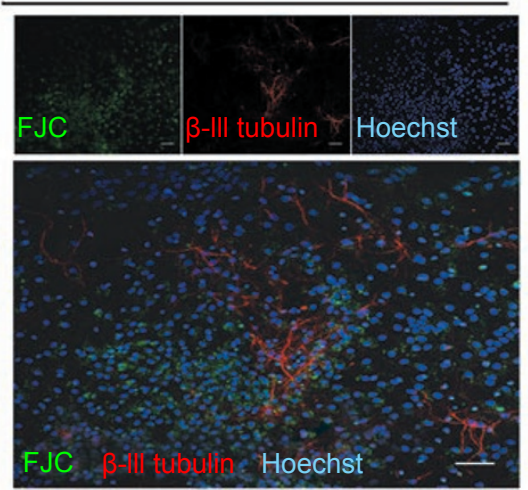

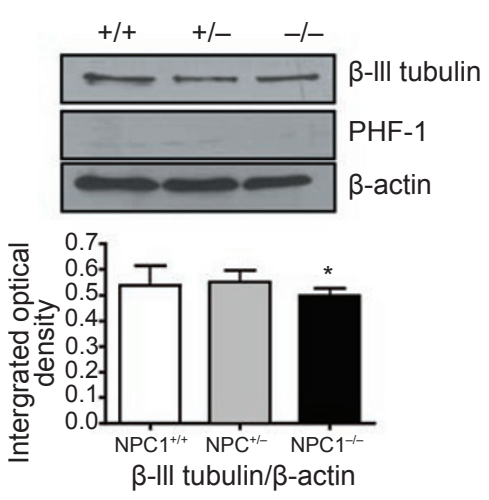

Figure $6 \mathrm{NSCs}$ from $\mathrm{NPC}^{-1-}$ mice in the presence of L-NAME had increased neuronal differentiation and reduced the number of partially neurodegenerative neurons. (A) NSCs from NPC1 $1^{--}$mice did not differentiate ( $\beta$-III tubulin, red). $\beta$-III tubulin protein levels were normalized to $\beta$-actin by Image J analysis software. Tau phosphorylation at Ser396/404 was represented by PHF-1 levels. Bar $=40 \mu \mathrm{m}$. (B) In the presence of $\mathrm{L}-\mathrm{NAME}$, NSCs from NPC1 $1^{--}$mice showed increased neuronal differentiation and decreased FJC expression. Bar $=40 \mu \mathrm{m}$. Mean \pm SD for 3-5 independent experiments. $P<0.05$.

pase-3 signaling pathway, changes in protein levels were examined via Western blot analysis. In the presence of L-NAME, iNOS protein was not detected in NSCs from $\mathrm{NPCl}^{-/-}$mice. We found that L-NAME inhibited the activation of GSK3 $\beta$ in NSCs from NPC1 $1^{-/}$homozygotes via phosphorylation at its Ser9 residue (Figure 5A-5C). Immunostaining revealed decreased levels of iNOS and p-GSK3 $\beta$-Tyr216 in $\mathrm{NPC1}^{-1-} \mathrm{NSCs}$ (Figure 5B). Treatment of $\mathrm{NPC}^{-1-}$ NSCs with L-NAME also decreased levels of cleaved caspase- 3 and changed p-p38 MAPK and p-AKT to wild-type levels (Figure 5A and 5D). L-NAME restored self-renewal and reduced neurodegenera-
tion in homozygous $N P C 1^{-1-} N S C s$

The presence of neurofibullary tangles (NFT) is one of the most common pathological markers for NPC disease [24]. GSK $3 \beta$ activation has been linked to NFT formation $[9,25]$. We examined the effects of NO on neurodegeneration and differentiation of NSCs in the murine model of NPC disease.
We performed immunochemical staining with FluoroJade C (FJC), a marker for degenerating neurons, and anti$\beta$-III tubulin, a neuronal marker. In NSCs from wild type, levels of $\beta$-III tubulin protein were significantly higher than $\mathrm{NPCl}^{-1-}$ mice. In wild type, levels of FJC were not detected, which suggested that these NSCs were differentiating into neurons with little degeneration.

In NSCs from $\mathrm{NPC}^{-/}$mice, FJC-positive degenerating neurons showed a concomitant decrease in $\beta$-III tubulin protein (Figure 6). In addition, homozygote $\mathrm{NPCl}^{--} \mathrm{NSCs}$ had increased levels of paired helical filaments (PHF-1), a major component of NFTs.

In the presence of L-NAME $(100 \mu \mathrm{M})$, the number of differentiated neurons increased, FJC signal decreased and PHF-1 protein levels decreased in homozygous $\mathrm{NPCl}^{-/}$ NSCs (Figure 6B). For the homozygotes, the reduction in number of neurodegenerative neurons might be due to increased differentiation of neurons and decreased cell death. These observations suggest that the NO inhibitor might reduce NFT formation in NPC disease by increasing 
self-renewal and differentiation of NSCs.

\section{Discussion}

Self-renewal of NSCs is essential to the development and maintenance of adult tissue [26]. Studies have shown that self-renewal is regulated by many factors [27, 28]. However, the mechanism of NSC self-renewal and differentiation is poorly understood. Few studies have studied the relationship between NSCs and neurodegenerative disease.

Previously we reported decreased self-renewal in NSCs derived from Niemann-Pick type C1 (NPC1)-deficient mice. In this study, we investigated the role of NO in NSC self-renewal and differentiation. Several recent studies proposed that NO was involved in the regulation of selfrenewal and differentiation in stem cells. For instance, Ellis et al. reported that NO modulates hematopoietic stem cell behavior, vascular phenotype in the retina and hemangioblast activity $[16,17]$. NO was shown to be a negative regulator of mammalian adult neurogenesis [29].

Studies in neural progenitor cells have shown that $\mathrm{p} 38$ MAPK mediates NO-induced apoptosis through the activation of caspase-3 [30]. In addition, it was shown that exogenous and endogenous NO (produced by eNOS and nNOS) impaired neurosphere formation and growth [4]. However, our study showed that iNOS activity might be involved in the impairment of self-renewal and differentiation of NSCs in $\mathrm{NPC1}^{-/-}$mice.

High NO levels might be caused by the accumulation of cholesterol. This accumulation may decrease self-renewal of NSCs from $\mathrm{NPCl}^{-/-}$mice. NPC1 gene mutation causes a defect in cholesterol delivery rate, resulting in cellular accumulation of unesterified cholesterol [31]. Several reports have indicated that lipoproteins, such as low-density lipoprotein (LDL), high-density lipoprotein (HDL) and ApoE, produce excessive NO that leads to neurodegeneration $[32,33]$.

Previous work in human astrocytoma cells suggested that LDL and HDL produced high levels of NO [34]. Moreover, lipoproteins from $\mathrm{AD}$ patients had increased levels of peroxynitrite and NOS, which suggested that the NO pathway may be a marker for $\mathrm{AD}$ [35]. NO rapidly reacts with the superoxide anion to form highly reactive peroxynitrite, which is associated with various physiological roles in neurodegenerative diseases, such as AD and Parkinson's disease (PD) [36, 37].

Moreover, NO induces tau hyperphosphorylation via GSK3 $\beta$ activation [21]. The inactivation of GSK3 $\beta$ has been shown to correlate with reduced degeneration in vivo [38]. The precise relationship between NO and GSK3 $\beta$ is not clear. Peroxynitrite induces nitration to regulate the p85 subunit of PI3 kinase [39]. Inhibition of PI3 kinase has been shown to regulate AKT/PKB activity and relieve the inhibition of GSK3 $\beta$ by phosphorylation at Ser9. GSK3 $\beta$ might modulate gene targets of Wnt, Hedgehog and Notch, which are important pathways in stem cell fate regulation $[39,40]$. Our data indicate that increased GSK3 $\beta$ activity by excessive NO might inhibit self-renewal of NSCs in NPC1-deficient mice. Overactivation of GSK3 $\beta$ in NSCs from $\mathrm{NPCl}^{--}$homozygous mice was likely caused by the induction of iNOS. This action might incite apoptosis through activation of caspase-3 (Figure 2).

The depletion of $\mathrm{NO}$ in the neurospheres from $\mathrm{NPC1}^{-/}$ restored NSC self-renewal (Figure 4). NO depletion also might reduce neurodegeneration through facilitation of differentiation and prevention of neuronal cell death. There is a lack of NO production in NPC fibroblast cells [41]. Differences between the effect of NO in NSCs and fibroblasts may be due to different cell types or tissue specificity.

Although NPC disease is a rare neurodegerative disease [42], NPC1 patients eventually die in adolescence due to the lack of an effective therapy that delays onset of disease or slows disease progression. NPC disease, a cholesterol metabolism disease, shares cellular pathology with other neurodegenerative diseases. For example, AD pathology includes NFT formation, lysosome system dysfunction and the actions of apolipoprotein E [44]. However, treatment of NPC patients with cholesterol-lowering drugs has not had significant effects on neurological symptoms [45]. Here, we presented data suggesting that the NO-mediated pathway regulates self-renewal and differentiation of NSCs and accelerates neurodegeneration in NPC disease. Therefore, NO might be a crucial pharmacological target in the treatment of this neurodegenerative disease. In addition, inhibition of $\mathrm{NO}$ activity could be used for in vivo or ex vivo expansion of NSCs [46, 47].

\section{Materials and Methods}

\section{Mice}

A breeding pair of BALB/c NPC1 ${ }^{N H}$ mice, heterozygous for $\mathrm{NPC} 1\left(\mathrm{NPCl}^{+/}\right)$, were purchased from Jackson Laboratories (Bar Harbor, MA, USA). All experiments were approved and regulated by the Institute of Laboratory Animals Resources (Seoul National University, Korea). For genotyping NSCs prepared from fetal mice, DNA was isolated from the tail and PCR was performed as described previously [12].

\section{Neurospheres cell culture}

For the neurospheres culture, fetal forebrain tissue from NPC transgenic mice was collected at day E16, as described previously [12]. Briefly, fetal cerebral tissue was mechanically triturated with Accumax (1X) (Chemicon, USA). Primary cells were cultured with DMEM/F12 media (Gibco, USA) supplemented with epidermal growth factor (EGF, $10 \mathrm{ng} / \mathrm{ml}$, Roche Applied Science, Germany), 
basic fibroblast growth factor (bFGF, $20 \mathrm{ng} / \mathrm{ml}$, Roche Applied Science), 1\% B27 supplement (Gibco), and a penicillin-streptomycin-neomycin antibiotic mixture $(100 \mu \mathrm{g} / \mathrm{ml}$, Gibco). Subsequent passaging of primary spheres was performed by application of the Accutase dissociating agent (Chemicon) to the spheres. The spheres were then centrifuged for $5 \mathrm{~min}$ (at $100 \times \mathrm{g}$ ), which dissociated them into a single-cell suspension. Dissociated single cells were incubated with $N^{\mathrm{G}}$-nitro-L-arginine methyl ester (L-NAME, Tocris, UK) or Spermine NONOate (SPNO, Tocris, UK) during the neurospheres culture. L-NAME and SPNO were dissolved in distilled water that was used for NO inhibition or NO donor during the NSCs culture.

\section{NO production}

For measuring NO production levels in the medium, the Griess reaction method was used according to the protocol of the Griess reagent system (Promega, USA). NO production was assessed by measurement of nitrite $\left(\mathrm{NO}_{2}^{-}\right)$levels, a stable and nonvolatile breakdown product of NO. Absorbance was measured at a wavelength of $550 \mathrm{~nm}$ using an EL800 universal microplate reader (Bio-Tek Instruments, USA). The nitrite concentration of samples was calculated from a standard curve of sodium nitrite.

\section{Immunofluorescence staining}

Neurospheres were fixed in 4\% paraformaldehyde for $20 \mathrm{~min}$. Cells were pre-incubated for $1 \mathrm{~h}$ with $10 \%$ normal goat serum (Zymed Laboratories Inc., USA). The neurospheres were stained with antibodies against iNOS (1:200, BD Bioscience, USA), pGSK3 $\beta$-Tyr216 (1:200, Santa Cruz Biotechnology, USA) and nestin (Chemicon, USA). Incubation in primary antibody was followed by $1 \mathrm{~h}$ incubation with species-appropriate secondary antibody, labeled with Alexa488 (1:1 000) or with anti-Alexa594 (1:1 000) (Molecular probe, USA). Nuclei were stained with Hoechst $33238(1 \mu \mathrm{g} / \mathrm{ml}$, $10 \mathrm{~min}$ ) after incubation with the secondary antibody. Images were captured on a confocal microscope (Nikon, Eclipse TE200, Japan).

\section{Fluoro Jade C (FJC) staining}

FJC (Chemicon, USA) is a neurodegenerative neuron marker that has been shown to stain degenerating neurons [48]. NSCs $\left(5 \times 10^{4} / \mathrm{ml}\right)$ differentiated into neurons for 6 days and then were fixed in $4 \%$ paraformaldehyde and incubated for $1 \mathrm{~h}$ with normal goat serum $(10 \%$, Zymed Laboratories Inc., USA), followed by incubation with anti- $\beta$ III tubulin antibody (Chemicon, 1:500) for $2 \mathrm{~h}$ at room temperature. Samples were then incubated with the secondary antibody (Alexa594, $1: 1000)$, FJC (0.0001\%) combined with the nuclear marker (Hoechst $33238,1 \mu \mathrm{g} / \mathrm{ml}$ ) in $0.1 \%$ acetic acid for $10 \mathrm{~min}$.

\section{Western blot analysis}

NSCs were lysed with a buffer $(150 \mathrm{mM} \mathrm{NaCl}, 20 \mathrm{mM}$ Tris- $\mathrm{HCl}$, $1 \mathrm{mM}$ EDTA) containing protease inhibitors $(1 \mathrm{mg} / \mathrm{ml}$ aprotinin, 1 $\mathrm{mM}$ leupeptin, $1 \mathrm{mM}$ PMSF) and phosphatase inhibitors (1 $\mathrm{mM}$ $\mathrm{NaVO}_{3}, 1 \mathrm{mM} \mathrm{NaF}$ ). Protein samples were separated by $10-15 \%$ SDS-PAGE and transferred to a nitrocellulose membrane. Immunoblotting was performed with antibodies against caspase-3, p38 MAPK, p-GSK3 $\beta$-Ser9 and GSK3 $\beta$ (Cell Signaling, USA), iNOS (BD Bioscience), p-p38 MAPK (Promega), $\beta$-III tubulin and PHF-1 (Chemicon) and $\beta$-actin (Sigma, 1:10 000). All primary antibodies were diluted 1:1000, except that $\beta$-actin antibody was diluted 1:10 000. Detection was by chemiluminescence.

\section{Statistical analysis}

Statistical analysis was performed using ANOVA followed by Duncan's multiple range tests. Values are given as mean \pm SD for 3-5 independent experiments. $P<0.05$ was considered significant.

\section{Acknowledgments}

This work was supported by a grant from the Korean Science \& Engineering Foundation (R01-2005-000-10190-0) and the BK21 Program for Veterinary Science.

\section{References}

1 Gage FH. Mammalian neural stem cells. Science 2000; 287:14331438.

2 Kleber M, Lee HY, Wurdak H, et al. Neural crest stem cell maintenance by combinatorial Wnt and BMP signaling. J Cell Biol 2005; 169:309-320.

3 Tokunaga A, Kohyama J, Yoshida T, et al. Mapping spatiotemporal activation of Notch signaling during neurogenesis and gliogenesis in the developing mouse brain. J Neurochem 2004; 90:142-154

4 Torroglosa A, Murillo-Carretero M, Romero-Grimaldi C, et al. Nitric oxide decreases subventricular zone stem cell proliferation by inhibition of epidermal growth factor receptor and phosphoinositide-3-kinase/Akt pathway. Stem Cells 2007; 25:88-97.

5 Covacu R, Danilov AI, Rasmussen BS, et al. Nitric oxide exposure diverts neural stem cell fate from neurogenesis towards astrogliogenesis. Stem Cells 2006; 24:2792-2800.

6 Sehara Y, Hayashi T, Deguchi K, et al. Distribution of inducible nitric oxide synthase and cell proliferation in rat brain after transient middle cerebral artery occlusion. Brain Res 2006; 1093:190-197.

7 Estrada C, Murillo-Carretero M. Nitric oxide and adult neurogenesis in health and disease. Neuroscientist 2005; 11:294-307.

8 Chung KK, Dawson VL, Dawson TM. S-nitrosylation in Parkinson's disease and related neurodegenerative disorders. Methods Enzymol 2005; 396:139-150.

9 Suzuki K, Parker CC, Pentchev PG, et al. Neurofibrillary tangles in Niemann-Pick disease type C. Acta Neuropathol (Berl) 1995; 89:227-238

10 Love S, Bridges LR, Case CP. Neurofibrillary tangles in Niemann-Pick disease type C. Brain 1995; 118(Pt 1):119-129.

$11 \mathrm{Yu}$ W, Gong JS, Ko M, et al. Altered cholesterol metabolism in Niemann-Pick type $\mathrm{C} 1$ mouse brains affects mitochondrial function. J Biol Chem 2005; 280:11731-11739.

12 Yang SR, Kim SJ, Byun KH, et al. NPC1 gene deficiency leads to lack of neural stem cell self-renewal and abnormal differentiation through activation of p38 mitogen-activated protein kinase signaling. Stem Cells 2006; 24:292-298.

13 Malinski T. Nitric oxide and nitroxidative stress in Alzheimer's disease. J Alzheimer's Dis 2007; 11:207-218.

14 Moncada S, Bolanos JP. Nitric oxide, cell bioenergetics and neurodegeneration. J Neurochem 2006; 97:1676-1689.

15 Heneka MT, Wiesinger H, Dumitrescu-Ozimek L, et al. Neuronal and glial coexpression of argininosuccinate synthetase and inducible nitric oxide synthase in Alzheimer disease. J Neuropathol Exp Neurol 2001; 60:906-916. 
16 Guthrie SM, Curtis LM, Mames RN, et al. The nitric oxide pathway modulates hemangioblast activity of adult hematopoietic stem cells. Blood 2005; 105:1916-1922.

17 Ellis EA, Sengupta N, Caballero S, et al. Nitric oxide synthases modulate progenitor and resident endothelial cell behavior in galactosemia. Antioxid Redox Signal 2005; 7:1413-1422.

18 Castillo SS, Levy M, Wang C, et al. Nitric oxide-enhanced caspase-3 and acidic sphingomyelinase interaction: a novel mechanism by which airway epithelial cells escape ceramideinduced apoptosis. Exp Cell Res 2007; 313:816-823.

19 Lu J, Moochhala S, Shirhan M, et al. Nitric oxide induces macrophage apoptosis following traumatic brain injury in rats. Neurosci Lett 2003; 339:147-150.

20 Cassina P, Peluffo H, Pehar M, et al. Peroxynitrite triggers a phenotypic transformation in spinal cord astrocytes that induces motor neuron apoptosis. J Neurosci Res 2002; 67:21-29.

21 Zhang YJ, Xu YF, Liu YH, Yin J, Wang JZ. Nitric oxide induces tau hyperphosphorylation via glycogen synthase kinase-3â activation. FEBS Lett 2005; 579:6230-6236.

22 Beurel E, Jope RS. The paradoxical pro- and anti-apoptotic actions of GSK3 in the intrinsic and extrinsic apoptosis signaling pathways. Prog Neurobiol 2006; 79:173-189.

23 Ghatan S, Larner S, Kinoshita Y, et al. p38 MAP kinase mediates bax translocation in nitric oxide-induced apoptosis in neurons. $J$ Cell Biol 2000; 150:335-347.

24 Auer IA, Schmidt ML, Lee VM, et al. Paired helical filament tau (PHFtau) in Niemann-Pick type C disease is similar to PHFtau in Alzheimer's disease. Acta Neuropathol (Berl) 1995; 90:547551.

25 Ohm TG, Treiber-Held S, Distl R, et al. Cholesterol and tau protein - findings in Alzheimer's and Niemann Pick C's disease. Pharmacopsychiatry 2003; 36(Suppl 2):S120-S126.

26 Molofsky AV, Pardal R, Morrison SJ. Diverse mechanisms regulate stem cell self-renewal. Curr Opin Cell Biol 2004; 16:700-707.

27 Molofsky AV, Pardal R, Iwashita T, et al. Bmi-1 dependence distinguishes neural stem cell self-renewal from progenitor proliferation. Nature 2003; 425:962-967.

28 Groszer M, Erickson R, Scripture-Adams DD, et al. PTEN negatively regulates neural stem cell self-renewal by modulating G0-G1 cell cycle entry. Proc Natl Acad Sci USA 2006; 103:111116.

29 Packer MA, Stasiv Y, Benraiss A, et al. Nitric oxide negatively regulates mammalian adult neurogenesis. Proc Natl Acad Sci USA 2003; 100:9566-9571.

30 Cheng A, Chan SL, Milhavet O, Wang S, Mattson MP. p38 MAP kinase mediates nitric oxide-induced apoptosis of neural progenitor cells. J Biol Chem 2001; 276:43320-43327.

31 Millard EE, Gale SE, Dudley N, et al. The sterol-sensing domain of the Niemann-Pick C1 (NPC1) protein regulates trafficking of low density lipoprotein cholesterol. J Biol Chem 2005; 280:28581-28590.

32 Danik M, Champagne D, Petit-Turcotte C, Beffert U, Poirier J.
Brain lipoprotein metabolism and its relation to neurodegenerative disease. Crit Rev Neurobiol 1999; 13:357-407.

33 Mahley RW, Weisgraber KH, Huang Y. Apolipoprotein E4: a causative factor and therapeutic target in neuropathology, including Alzheimer's disease. Proc Natl Acad Sci USA 2006; 103:5644-5651

34 Nanetti L, Vignini A, Moroni C, Pessina GP, Mazzanti L. LDL and HDL affect nitric oxide metabolism in human astrocytoma cells. Brain Res 2004; 1020:173-177.

35 Nanetti L, Vignini A, Moroni C, et al. Peroxynitrite production and NOS expression in astrocytes U373MG incubated with lipoproteins from Alzheimer patients. Brain Res 2005; 1054:3844.

36 Katsuki H, Okawara M, Shibata H, Kume T, Akaike A. Nitric oxide-producing microglia mediate thrombin-induced degeneration of dopaminergic neurons in rat midbrain slice culture. $J$ Neurochem 2006; 97:1232-1242.

37 Castegna A, Thongboonkerd V, Klein JB, et al. Proteomic identification of nitrated proteins in Alzheimer's disease brain. J Neurochem 2003; 85:1394-1401.

38 Noble W, Planel E, Zehr C, et al. Inhibition of glycogen synthase kinase- 3 by lithium correlates with reduced tauopathy and degeneration in vivo. Proc Natl Acad Sci USA 2005; 102:6990-6995.

39 Trowbridge JJ, Xenocostas A, Moon RT, Bhatia M. Glycogen synthase kinase-3 is an in vivo regulator of hematopoietic stem cell repopulation. Nat Med 2006; 12:89-98.

40 Israsena N, Hu M, Fu W, Kan L, Kessler JA. The presence of FGF2 signaling determines whether $\beta$-catenin exerts effects on proliferation or neuronal differentiation of neural stem cells. Dev Biol 2004; 268:220-231.

41 Mani K, Cheng F, Fransson LA. Defective nitric oxide-dependent, deaminative cleavage of glypican-1 heparan sulfate in NiemannPick C1 fibroblasts. Glycobiology 2006; 16:711-718.

42 Vance JE. Lipid imbalance in the neurological disorder, NiemannPick C disease. FEBS Lett 2006; 580:5518-5524.

43 Vanier MT, Millat G. Niemann-Pick disease type C. Clin Genet $2003 ; \mathbf{6 4}: 269-281$.

44 Nixon RA. Niemann-Pick Type C disease and Alzheimer's disease: the APP-endosome connection fattens up. Am J Pathol 2004; 164:757-761.

45 Erickson RP, Garver WS, Camargo F, Hossain GS, Heidenreich RA. Pharmacological and genetic modifications of somatic cholesterol do not substantially alter the course of CNS disease in Niemann-Pick C mice. J Inherit Metab Dis 2000; 23:54-62.

46 Fink JK, Filling-Katz MR, Sokol J, et al. Clinical spectrum of Niemann-Pick disease type C. Neurology 1989; 39:1040-1049.

47 Griffin LD, Gong W, Verot L, Mellon SH. Niemann-Pick type C disease involves disrupted neurosteroidogenesis and responds to allopregnanolone. Nat Med 2004; 10:704-711.

48 Schmued LC, Stowers CC, Scallet AC, Xu L. Fluoro-ade C results in ultra high resolution and contrast labeling of degenerating neurons. Brain Res 2005; 1035:24-31.

(Supplementary Information is linked to the online version of the paper on the Cell Research website.) 